\title{
Fatal and non-fatal farm injuries to children and adolescents in the United States, 1990-3
}

Frederick P Rivara

\begin{abstract}
Objective-Examine the current magnitude of the injury problem to children and adolescents on farms, and to compare these data to that from 1978-83.
\end{abstract}

Data sources-US National Center for Health Statistics Mortality Multiple Cause of Death Tapes for the years 1991-3, and the US Consumer Product Safety Commission National Electronic Injury Surveillance System for data on emergency department visits for 1990-3.

Subjects-Children and adolescents 19 years and younger injured on farms.

Results-There were an average of 104 deaths per year due to injuries occurring on farms. The rate of 8.0 deaths per 100000 child farm residents is $39 \%$ lower than in 1979-81. More of the deaths occurred in hospital than previously. There were an average of 22288 emergency department treated injuries per year. The rate of 1717 injuries per 100000 child farm residents is $10.7 \%$ higher than 1979-83. Males were injured more frequently than females. Tractors accounted for $20.9 \%$ of all injuries, followed by horses $(8.4 \%)$, all terrain vehicles and minibikes $(8.0 \%)$, and farm wagons (7.7\%).

Conclusions-Farm injuries continue to be a major problem to children living on farms. While improved medical care may have contributed to the reduction in mortality, the continued high rate of injuries warrants study of a variety of intervention strategies to reduce the injury toll. There is also a need for ongoing injury surveillance to provide accurate data on the farm injury problem.

(Injury Prevention 1997; 3: 190-194)

Keywords: farm; tractors; farm equipment; rural.

Agriculture is one of the most dangerous occupations in the United States, ${ }^{1}$ and unlike other industries, children and adolescents make up a substantial portion of the agricultural workforce. In addition, by virtue of the fact that children and adolescents live on farms, they are constantly exposed to the hazards of farm equipment, regardless of whether or not they are working. This is qualitatively different from other industries in which children have little, if any, exposure to occupational hazards.

In recent years, there has been greater attention to the problem of agriculture related injuries and illnesses to children living and working on farms. A National Committee for능 Childhood Agricultural Injury Prevention (NCCAIP) was formed and issued 13 recom-त्ष mendations to prevent farm injuries to children in the form of a national action plan. ${ }^{2}$ The Maternal and Child Health Bureau has estab- $\overrightarrow{0}$ lished a Rural Injury Prevention Resource Center with a major focus on farm injuries. Grassroots groups, such as Farm Safety 4 Justo Kids, have been formed to increase public awareness of the magnitude of the problem; conduct public education, and lobby foro legislation and regulation. ${ }^{3}$

In spite of this, there have been relatively few studies of the incidence of farm injuries $s$ nationally. This study was undertaken to? examine the current magnitude of the injury problem to children and adolescents on farms and to compare these data with those analyzed previously. ${ }^{4}$

\section{Methods}

DATA SOURCES

The data sources used for the analyses were as: follows:

(1) National Center for Health Statisticso (NCHS) Mortality Multiple Cause of Death Tapes. The most recent tapes available were for the years 1991, 1992, and 1993. These tapes are based on information received by the NCHS from all states and the District of Columbia. The cause of death was listed by the? International Classification of Diseases, adapted revision 9 (ICDA-9) codes. The data include all fatalities to children and adolescents 199 years of age or younger with external cause of death codes of E850 to E929 that occurred on a farm, including farm homes. These onlyo included non-transport fatalities, because transport fatalities cannot be separated as tof place of injury. This same data source was used previously to calculate fatality rates for 1979 81.4

(2) National Electronic Injury Surveillances System (NEISS) of the Consumer Product Safety Commission (CPSC). NEISS is $a^{\omega}$ surveillance system of consumer product re $<$ lated injuries treated in hospital emergencye departments located in the United States. Thes surveillance system is a statistically representative sample of emergency rooms, and thus allows estimates of non-motor vehicle related injuries involving consumer products. TapesD on injuries involving farm products to individuals 19 years of age or less during the years 1990-3 were analyzed. Data were not analyzed for the period after 1993 because of changes in data collection methods and scope of the NEISS sample. This same data source was used previously to estimate non-fatal injury rates for $1979-83 .{ }^{4}$ The NEISS data
Center, Box 359960,325

Ninth Ave, Seattle, WA 98104, USA. 
indicate morbidity due to farm related products occurring to these individuals, irrespective of location, with the exception of animal and all terrain vehicle (ATV) injuries, which were analyzed for farm locations only. This was done to make the study comparable with the 1985 report.

The denominators for the rate calculations were the number of children and adolescents 19 years of age and younger reported to be living on farms in the 1991 census. $^{5}$

\section{Results}

\section{NCHS DEATH CERTIFICATE DATA}

An estimated 1298000 children and adolescents 19 years of age or younger were living on farms in 1991. There were an average of 104 deaths per year due to injuries occurring on farms to individuals in this age group, a rate of 8.0 deaths per 100000 population per year (table 1). Males had 5.6-fold higher rates of death than females, although this varied by a ratio of 3.7 in children under the age of 5 to 9.9 in adolescents $15-19$ years old.

This represents a $39 \%$ reduction in the rate of fatal injuries to children and adolescents on the farm compared with the rate of 13.2 per 100000 in $1979-81$. The rate declined in males and females equally; rates declined least for children under the age of $5(29 \%)$ and most for children $10-14$ years $(47 \%)$.

Nearly one half of children died in the hospital and an additional $13.8 \%$ were pronounced dead on arrival (table 1). Out-ofhospital deaths accounted for $38.6 \%$ of fatalities, although this varied from $16.7 \%$ of young children to $55.4 \%$ of teens $15-19$ years. The place of death was unknown in only $1.6 \%$.

These statistics are substantially different from a decade earlier in which only $15 \%$ of children and adolescents died in the hospital and one half died out of hospital. It indicates that, in all likelihood, emergency medical services in rural areas have improved substantially.

Deaths were most common in the Midwest $(41.8 \%)$ and the South $(35.3 \%)$ and least common in the Northeast $(7.7 \%)$ and the West $(15.1 \%)$.

Table 1 Fatal farm injuries to children and adolescents in the United States, 1991-3, NCHS data, 0-19 years, average annual deaths

\begin{tabular}{|c|c|c|c|c|c|}
\hline & \multicolumn{5}{|c|}{ Age (years) } \\
\hline & $<5$ & $5-9$ & $10-14$ & $15-19$ & $\overline{\text { Total }}$ \\
\hline \multicolumn{6}{|c|}{ Annual No of deaths } \\
\hline Male & 21.0 & 17.7 & 20.0 & 31.0 & 89.7 \\
\hline Female & 5.0 & 3.3 & 3.0 & 2.7 & 14.0 \\
\hline Total & 26.0 & 21.0 & 23.0 & 33.7 & 103.7 \\
\hline \multirow{2}{*}{\multicolumn{6}{|c|}{$\begin{array}{l}\text { Annual rate per } 100000 \\
\text { farm resident children }\end{array}$}} \\
\hline & & & & & \\
\hline Male & 11.9 & 10.5 & 11.9 & 17.2 & 13.0 \\
\hline $\begin{array}{l}\text { Female } \\
\text { Total }\end{array}$ & $\begin{array}{l}3.2 \\
7.8\end{array}$ & $\begin{array}{l}2.2 \\
6.6\end{array}$ & $\begin{array}{l}2.0 \\
7.3\end{array}$ & $\begin{array}{r}1.8 \\
10.2\end{array}$ & $\begin{array}{l}2.3 \\
8.0\end{array}$ \\
\hline \multicolumn{6}{|l|}{ Place of death (\%) } \\
\hline Inpatient & 30.8 & 20.6 & 7.2 & 14.9 & 18.3 \\
\hline Outpatient/ED & 37.2 & 27.0 & 29.0 & 19.8 & 27.7 \\
\hline DOA & 15.4 & 17.5 & 17.4 & 7.9 & 13.8 \\
\hline Out of hospital & 16.7 & 30.2 & 46.4 & 55.4 & 38.6 \\
\hline Unknown & 0 & 4.8 & 0 & 2.0 & 1.6 \\
\hline
\end{tabular}

The external cause of death, as documented in the $\mathrm{E}$ codes, is shown in table 2. Farm machinery was involved in one third of the deaths, with the highest proportion among children 5-9 years. Drowning accounted for one fourth of the deaths overall, and one third of those to the youngest children. One in seven died from firearms or explosives; among teens, firearms and explosives accounted for fully one quarter of all deaths. The remainder of deaths were caused by a wide variety of mechanisms.

The most common injury resulting in death was to the head or brain, accounting for nearly two thirds of the total (table 3). Other common causes of fatal injury were to the chest or abdomen. Neck injuries were uncommon. Only $2 \%$ died from burns.

\section{NEISS EMERGENCY DEPARTMENT DATA}

The data from NEISS for the most part represent non-fatal, morbidity data. There were an estimated 89153 injuries treated in an emergency department for the years 19903 which involved farm related products or animals on farms as defined above. The mean number of emergency department treated injuries was 22288 per year, which is $5 \%$ lower than the estimated annual number reported for the period 1979-83. However, because of a smaller child and adolescent farm population in the latter period, the rate of farm injuries was actually $10.7 \%$ higher, 1717 per 100000 compared with 1551 per 100000 during the earlier time period.

As expected, rates of injuries varied with age and gender as shown in table 4. Males had 2.4-

Table 2 Fatal farm injuries to children and adolescents in the United States, 1991-3, NCHS data, 0-19 years, cause of death by age (\%)

\begin{tabular}{lcrrrr}
\hline & \multicolumn{7}{l}{ Age (years) } \\
\cline { 2 - 6 } Cause & \multicolumn{1}{c}{5} & \multicolumn{1}{c}{$5-9$} & \multicolumn{1}{c}{$10-14$} & $15-19$ & Total \\
\hline Machinery & 35.9 & 46.0 & 34.8 & 24.8 & 34.1 \\
Drowning & 32.1 & 23.8 & 11.6 & 26.7 & 24.1 \\
Suffocation & 1.3 & 0 & 7.3 & 1.0 & 2.3 \\
Falls & 6.4 & 3.2 & 5.8 & 3.0 & 4.5 \\
Firearms/explosives & 3.9 & 4.8 & 21.7 & 25.7 & 14.8 \\
Electrical & 1.3 & 1.6 & 4.3 & 1.0 & 1.9 \\
Other & 19.2 & 17.5 & 14.5 & 17.8 & 18.0 \\
\hline
\end{tabular}

Table 3 Fatal farm injuries to children and adolescents in the United States, 1991-3, NCHS data, 0-19 years, parts of body injured

\begin{tabular}{lr}
\hline Body part & $\%$ \\
\hline Head & 40.2 \\
Brain & 24.1 \\
Neck & 1.9 \\
Face & 7.4 \\
Trunk & 26.0 \\
Upper extremity & 1.6 \\
Lower extremity & 4.2 \\
\hline
\end{tabular}

Table 4 National estimates of annual farm injuries in the United States, 1990-3, 0-19 years, rates per 100000 resident farm children

\begin{tabular}{lccc}
\hline Age (years) & Male & Female & Total \\
\hline$<5$ & 1214 & 660 & 953 \\
$5-9$ & 1884 & 1107 & 1518 \\
$10-14$ & 2923 & 1239 & 2135 \\
$15-19$ & 3399 & 944 & 2279 \\
All ages & 2360 & 983 & 1717 \\
\hline
\end{tabular}


fold greater rates than females, with the greatest difference in the adolescent years, when males had 3.6-fold higher rates. Children 10 and older had substantially higher rates than did the younger age groups.

Lacerations and punctures were the most common injuries, followed by contusions, abrasions, and hematomas (table 5). One in five injuries was a fracture of a dislocation with children 10-14 years having a rate nearly twice that of any other age group.

Approximately one third of the injuries were to the upper extremities and another $30.8 \%$ were to the lower extremities (table 6). Young children were more likely to have injuries to the head or face, while older adolescents had injuries primarily to the extremities.

The majority of individuals (89.8\%) were treated in the emergency department and released. Approximately 4\% were transferred to another facility, and $5.6 \%$ were admitted. Children under the age of 5 and those 10-14 years were more likely to be admitted than were children in other age groups $(7.7 \%$ and $7.5 \%$, respectively). Overall, $0.3 \%$ of children died in the emergency department.

There was a wide variety of products involved in farm injuries (table 7). Tractors accounted for one in five injuries overall, but one in three injuries to children under the age of 5. Farm wagons, tillage equipment, and

Table 5 National estimates of annual farm injuries by type of injury in the United States, $1990-3,0-19$ years, rates per 100000 resident farm children (\%)

\begin{tabular}{|c|c|c|c|c|c|}
\hline \multirow[b]{2}{*}{ Type } & \multicolumn{5}{|l|}{ Age (years) } \\
\hline & $<5$ & $5-9$ & $10-14$ & $15-19$ & $\overline{\text { Total }}$ \\
\hline $\begin{array}{l}\text { Lacerations/punctures } \\
\text { Dislocations/fractures } \\
\text { Contusions/abrasions/hematomas } \\
\text { Crush } \\
\text { Strains/sprains } \\
\text { Avulsions/amputations } \\
\text { Burns } \\
\text { Concussions } \\
\text { Other }\end{array}$ & $\begin{array}{l}378(40.4) \\
118(12.6) \\
182(19.4) \\
17(1.8) \\
3(0.3) \\
11(1.2) \\
51(5.5) \\
8(0.9) \\
185(19.4)\end{array}$ & $\begin{array}{r}574(36.9) \\
282(18.6) \\
351(23.2) \\
27(1.8) \\
65(4.3) \\
45(3.0) \\
45(3.0) \\
8(0.5) \\
121(8.0)\end{array}$ & $\begin{array}{l}801(37.6) \\
449(21.1) \\
474(22.2) \\
24(1.1) \\
161(7.6) \\
27(1.2) \\
43(1.4) \\
37(1.8) \\
119(5.6)\end{array}$ & $\begin{array}{l}829(36.4) \\
291(12.8) \\
589(25.9) \\
33(1.5) \\
227(10.0) \\
76(5.0) \\
59(2.6) \\
9(0.4) \\
166(7.3)\end{array}$ & $\begin{array}{l}644(37.6) \\
283(19.5) \\
398(23.3) \\
25(1.5) \\
114(6.7) \\
49(2.9) \\
39(3.0) \\
15(0.9) \\
150(8.7)\end{array}$ \\
\hline
\end{tabular}

Table 6 National estimates of annual farm injuries by body part and age group in the United States, 1990-3 (\%)

\begin{tabular}{lrrrrr}
\hline \multicolumn{5}{c}{ Age (years) } \\
\cline { 2 - 6 } Body part & \multicolumn{1}{c}{5} & $5-9$ & $10-14$ & $15-19$ & Total \\
\hline Head & 17.4 & 12.0 & 5.2 & 5.9 & 8.7 \\
Neck & 0 & 1.8 & 0.9 & 1.9 & 1.3 \\
Face & 29.4 & 15.7 & 15.0 & 5.9 & 8.7 \\
Trunk & 5.7 & 7.8 & 7.9 & 5.6 & 6.8 \\
Upper extremity & 28.7 & 28.8 & 29.1 & 36.3 & 31.4 \\
Lower extremity & 9.3 & 28.2 & 39.4 & 33.9 & 30.8 \\
Other & 9.5 & 5.7 & 2.5 & 3.5 & 4.5 \\
\hline
\end{tabular}

Table 7 Proportion of farm injuries by product in each age group in the United States, 1990-3 (\%)

\begin{tabular}{lrrrrr}
\hline & \multicolumn{2}{l}{ Age (years) } & & & \\
\cline { 2 - 6 } Product & \multicolumn{1}{c}{$<$} & \multicolumn{1}{c}{$5-9$} & $10-14$ & $15-19$ & Total \\
\hline Tractor & 33.4 & 20.8 & 15.9 & 20.2 & 20.9 \\
Tillage equipment & 9.1 & 5.9 & 3.2 & 7.7 & 6.2 \\
Combines/threshers/hay processors & 2.6 & 6.6 & 2.5 & 6.3 & 4.7 \\
Elevators/conveyers & 2.3 & 0.6 & 0.9 & 1.6 & 1.3 \\
Farm wagons & 5.4 & 10.9 & 8.8 & 5.7 & 7.7 \\
Forklifts & 3.3 & 2.9 & 2.4 & 1.3 & 2.3 \\
Fertilizers & 9.6 & 2.7 & 0.5 & 0.4 & 2.2 \\
Silo loaders & 1.3 & 2.6 & 1.8 & 1.4 & 1.7 \\
Horseback riding & 3.2 & 9.4 & 10.7 & 7.9 & 8.4 \\
ATV/trail bikes/minibikes & 0.9 & 5.9 & 12.0 & 8.8 & 8.0 \\
Other & 28.9 & 31.8 & 41.3 & 38.8 & 36.6 \\
Total & 100.0 & 100.0 & 100.0 & 100.0 & 100.0 \\
\hline
\end{tabular}

other farm machinery were also frequent causes of injuries. Horseback riding on farms accounted for $8.4 \%$ of injuries and riding motorized vehicles such as ATVs, minibikes and trail bikes accounted for another $8 \%$ There was a wide variety of products in the. other category; none of these products singl accounted for more than $2 \%$ of injuries.

NEISS classifies injury severity based of type of injury, body part involved and require $\overline{\bar{\sigma}}$ ment for admission. Two thirds of the injurie were of low severity. However, younger chil dren were less likely to have injuries in the lowest severity category $(51.4 \%)$ than an $\vec{P}$ other age group, especially when compaređ with those $10-19$ years $(72.2 \%)$. The proporo tion of children with severe injuries was highest for tillage equipment (13.9\%), and silo loader $(13.8 \%)$, followed by combines and hay processing equipment $(12.2 \%)$, and forklifts $(11.1 \%)$.

\section{Discussion}

Rates of death from farm injuries appear to have declined substantially over the last decक्ष ade. The rate in $1990-3$ was $39 \%$ lower than the rate in 1979-81. Fatal farm injuries foun 80 in smaller population based studies range from 2.3 to 30.9 per 100000 residents. $^{6}$ There are probably multiple reasons for this decline including better emergency medical service care, better trauma care, and increased pre vention. The fact that now nearly one half of children who die from farm injuries die in th $\overrightarrow{\vec{E}}$ hospital compared with only $15 \%$ a decade ag $\widehat{乛}$ indicates that emergency medical services have substantially improved. More injury victims are. being transported to hospitals faster, allowin $\overline{\mathrm{g}}$ them to be resuscitated from their injuries during the first 'golden' hour, with a resulting improvement in outcome. Regionalized trau ma care may have also contributed to the decline in mortality. Other studies have showr? a substantial effect of regionalized systems iñ both urban and rural areas. ${ }^{78}$

Prevention efforts may have also contribute $\mathscr{\otimes}$ to this decline. One third of the fatal injuries were due to machinery; other studies indicate that the most common cause of farm machine related deaths are due to tractors. ${ }^{9}$ Rollove protective structures are effective in preventing these deaths, ${ }^{10}$ and there have been majo efforts in recent years to promote their use.

The decline in deaths of children from farm related injuries is also consistent with the decline in unintentional injuries from othe? causes. During the 14 year period 1978-91@ unintentional injuries to children and adoles:cents in the United States declined by $30 \% .1+10$ This decline is, as with farm injuries, likely to be due to a combination of better emergencex medical service and trauma care, as well as the effects of prevention programs such as car seats and smoke detectors. The decline in drowning deaths of children and adolescents that have occurred, both on the farm and elsewhere, is due at least in part to better emergency medica $\vec{\Gamma}$ service care. In addition, some of the decline in fatal injuries may be due to decreases in 
exposure to risk. In contrast, the proportion of deaths due to guns is higher in this time period than that reported previously and, in all probability, reflects continued exposure to guns around the home and farm.

In contrast, there has been a $10 \%$ increase in the incidence of non-fatal farm injuries as reported in NEISS. The rate of child and adolescent farm injuries found using the NEISS data is similar to that of other recent studies. Stueland et al conducted a population based surveillance of farm injuries occurring to children and adolescents under 18 years of age in Wisconsin. ${ }^{12}$ Their rate of farm injuries was 1827 per 100000 , very similar to our rate of 1717 per 100000 . Pickett et al found a rate of self reported injuries to children on farms in Ontario of 2000 per 100000 per year, ${ }^{13}$ again close to our rate using NEISS data, but higher because the Ontario data include all injuries on farms, not just those related to farm products.

The occurrence of these injuries varies substantially with age. The high number of injuries in preschool aged children, combined with greater severity, is of concern. These children are injured as innocent bystanders because the place where they live is also the site of a dangerous workplace. Thus, their exposure to the risks of the workplace is high, without their direct participation in farm work. In addition, some of these injuries occur when the children are taken along with adults or older siblings on tractors, or while working around other machinery. This may reflect a lack of other child care options, but may also reflect the desire to 'treat' the child to a ride on a tractor or other farm equipment. Similar injury consequences are seen when children are taken on riding lawn mowers, making this the most common cause of amputation injuries to toddlers in a recent study. ${ }^{14}$

The high rate of injuries to the $10-14$ year age group is likely work related. The exposure to farm work in this younger age group is lower than that for older adolescents. Thus, the rate of injuries in 10-14 year olds indicates greater risk due to inexperience working with farm equipment. It may also indicate physical immaturity, in terms of size and weight, to safely operate farm equipment.

Injuries to children and adolescents are more severe than those occurring in other areas of child labor. Heyer et al found that in Washington state, farm workers accounted for $7 \%$ of worker's compensation claims, but among workers age 13 and under accounted for $50 \%$ of all severe injury claims and $48 \%$ of all disabling injury claims. ${ }^{15}$

The problem of ATVs, trail bikes, and minibikes is well known. ${ }^{16}$ These motorized vehicles are used around the farm for both work and recreation. The speeds attained and the lack of safeguards make them dangerous. The American Academy of Pediatrics has strongly endorsed their removal from the market. In 1988, the ATV industry arrived at an agreement with the CPSC that stopped the sale of new three wheeled ATVs, implemented a nationwide riders' training program, and developed voluntary standards to make ATVs safer. There appeared to be a $7 \%$ reduction in ATV related injuries and a $9 \%$ reduction in fatalities over the 1988-90 time period associated with these regulations. ${ }^{17}$ Nevertheless, some injuries continue to occur.

Injuries on farms occur to children in other parts of the world, and the patterns in industrialized countries are similar to those in the United States. Tractors were responsible for one fourth of farm related deaths to children in the UK. ${ }^{18}$ Tractors and farm machines caused the majority of severe and fatal injuries in a case series from France. ${ }^{19}$ Reports from Manitoba ${ }^{20}$ and New South Wales $^{21}$ indicate that animals are a common source of injuries, particularlý among young girls. In less industrialized countries such as India, a larger portion of farm injuries to children involve hand tools. ${ }^{22}$ As in the United States, ongoing surveillance systems to provide accurate population based data on child farm injuries are rare.

\section{Limitations}

There are a number of limitations that must be addressed. The denominator for these calculations includes only children and adolescents living on farms. It is estimated that there are more than one half million migrant workers under age 21 or children of migrant workers traveling with their parents. ${ }^{23}$ Unfortunately, there are no accurate data on the total number of children and adolescents who either live or work on farms. Thus, exclusion of these individuals potentially overestimates the rate of injuries. At least one report found that $95 \%$ of the injuries occurred to children from the immediate farm family. ${ }^{24}$ Other studies estimate that one third to one half of injuries on the farm are not to residents. ${ }^{25}$

I have not attempted to determine which injuries occurred during farm work, and those that occurred while simply being exposed to the hazards on farms. Thus, the rates should not be construed to indicate child labor related trauma. On the other hand some injuries, such as motor vehicle crashes due to farm work, were excluded because of the impossibility of separating out vehicular crashes on farm roads and those on other roads. This is an important limitation since motor vehicle crashes are an important source of occupational injuries and, for migrant farm workers, may be the leading cause.

The NEISS data are based on a representative sample of hospital emergency departments in the United States. However, the sample does not necessarily reflect hospitals located in rural areas. This may be particularly true for pediatric injuries, in that the NEISS hospitals specializing in pediatric care are primarily located in urban areas.

The fatality data, while complete, may not accurately record the place of occurrence of death. Other deaths to farm children may have also been missed if the place of occurrence was listed differently. The data include only fatal injuries or those treated in the emergency department. There are few American data on 
injuries treated in physicians' offices. Pickett et al estimated that approximately $68 \%$ of farm injuries receive medical care and only $28 \%$ receive care in the emergency department. ${ }^{13}$ Thus, the data presented here represent only a portion of the actual farm injury problem.

\section{Implications for prevention}

Prevention of farm injuries to children and adolescents is possible with a multifaceted approach such as that put forward by the NCCAIP. This proposed national action plan calls for: the establishment of a national surveillance system to detect and track injury rates; to establish a national database on agricultural injuries; guidelines for children's and adolescents' work in agriculture; uniform standards to protect young workers from agricultural hazards, with appropriate enforcement of regulations; the development and evaluation of intervention programs to educate parents, owners, operators, and youth themselves on safe farm practices; and adequate support from the public and private sector. As with other injury problems, farm related injuries to children and adolescents should be viewed as preventable and not accepted as the cost of a hazardous environment.

This study was supported by a grant from Farm Safety 4 Jus Kids and from the National Center for Injury Prevention and Control, Centers for Disease Control and Prevention. Thanks to Marilyn Adams, founder and President of Farm Safety 4 Just Kids, for commissioning this study and for comments on it, to Art McDonald and Tom Schroder of the CPSC for providing the NEISS data, to Bob Soderberg for computer programming, and to Barbara Lee for her helpful review of the manuscript. Presented in part at the 10 Year Anniversary Meeting of Farm Safety Just 4 Kids, February 1997.

1 National Safety Council. Accident facts: 1996 edition. Chicago: National Safety Council, 1996.

2 National Committee for Childhood Agricultural Injury Prevention. Children and agriculture; opportunities for safety and health. Marshfield, WI: Marshfield Clinic, 1996.

3 Farm Safety 4 Just Kids. Strategic plan. Earlham, IA: Farm Safety 4 Just Kids, 1996.

4 Rivara FP. Fatal and non-fatal farm injuries to children and adolescents in the United States. Pediatrics 1985; 76: 567-73.

5 Dacquel LT, Dahmann DC. Residents of farms and rural areas: 1991. Washington, DC: US Government Printing Office, US Bureau of Census, Current Population Office, US Bureau of

6 Stallones L, Gunderson P. Epidemiological perspectives on childhood agricultural injuries within the United States fournal of Agromedicine 1994; 1: 3-18.

7 Svenson JE, Spurlock C, Nypaver M. Factors associated wit the higher traumatic death rate among rural children. Anfo Emerg Med 1996; 27: 625-32.

8 Maio RF, Burney RE, Gregor MA, Baranski MG. A study of preventable trauma mortality in rural Michigan. $\mathcal{f}$ Traum 1996; 41: 83-90.

9 Dunn KA, Runyan CW. Deaths at work among children an adolescents. Am f Dis Child 1993; 147: 1044-7.

10 Centers for Disease Control. Public health focus: effective ness of rollover protective structures for preventings injuries associated with agricultural tractors. MMWR injuries associated

11 Rivara FP, Grossman DC. Prevention of traumatic injuries to children and adolescents: how far have we come andw where do we need to go? Pediatrics 1996; 97 (6 pt 1): 791 -

12 Stueland DT, Lee BC, Nordstrom DL, Layde PM, Wittman LM. A population based case-control study of agriculturat injuries in children. Injury Prevention 1996; 2: 192-6.

13 Pickett W, Brison RJ, Niezgoda H, Chipman ML. Nonfatalo farm injuries in Ontario: a population-based study. Acci Anal Prev 1995; 27: 425-33.

14 Trautwine L, Smith D, Rivara FP. Pediatric amputation injuries: etiology, cost and outcome. $\mathcal{F}$ Trauma 1996; 41:831-8.

15 Heyer NJ, Franklin G, Rivara FP, Parker P, Haug JA Occupational injuries among minors doing farm work in Washington state: 1986 to 1989 . Am f Public Health 1992 82: $557-60$

16 Dolan MA, Knapp JF, Andres J. Three-wheel and foure wheel all-terrain vehicles in children. Pediatrics 1989; 84: 694-8.

17 Rodgers GB. All-terrain vehicle injury risks and the effects of regulation. Accid Anal Prev 1993; 25: 335-46.

18 Cameron D, Bishop C, Sibert JR. Farm accidents in children. $B M 71992 ; 305: 23-5$.

19 Vanneuville G, Corger H, Tanguy A, Dalens B, Scheye Ts Floucaud D. Severe farm injuries to children-a report on 15 cases. Eur $\mathcal{f}$ Pediatr Surg 1992; 2: $29-31$

20 Young SK. Agriculture related injuries in the parklanof region of Manitoba. Can Fam Physician 1995; 41: 1141 region of Manit

21 Wolfenden K, McKenzie A, Sanson-Fisher RW. Identifying hazards and risk opportunities in child farm injury. Aust Public Health 1992; 16: 122-8.

22 Singh AJ, Kaur A. Minor injuries in ninth class schoo? children of Chandigarth and rural Haryana. Indian Pediati 1996; 33: $25-30$

23 National Commission on Migrant Education. Invisible children: a portrait of migrant education in the USC Waring

24 Stueland D, Layde P, Lee BC. Agricultural injuries in children in central Wisconsin. $\mathcal{f}$ Trauma 1991; 31: 1503-(D) 9.

25 Nordstrom DL, Layde PM, Olson KA, Stueland D, Bran $\mathrm{L}$, Follen MA. Incidence of farm-work-related acut injury in a defined population. Am $\mathcal{F}$ Ind Med 1995; 28: $551-64$.

\section{Soft landing}

A boy aged 3 who toppled from a first floor window at his home in Leicester fell safely on to the family dog, which was dozing on the patio. Michael suffered only scratches and a bumped head while Duke, a mongrel, walked away unhurt (The Times, 25 June 1997).

Editor's note: at least the television news coverage of this story noted that the parents thought that they should now fit locks on the window. For non-British readers, I should point out that the first floor is the one above the ground floor, so the fall would have been from about 3 metres. 